\title{
GMR
}

\section{Sperm quality and DNA damage in men from Jilin Province, China, who are occupationally exposed to ionizing radiation}

\author{
D.D. Zhou ${ }^{1,2}$, J.L. $\mathrm{Hao}^{3}$, K.M. Guo ${ }^{4}$, C.W. Lü ${ }^{3}$ and X.D. Liu' ${ }^{1}$ \\ ${ }^{1}$ Key Laboratory of Radiobiology (Ministry of Health), School of Public Health, \\ Jilin University, Changchun, China \\ 2Department of Radiology, First Hospital of Jilin University, Changchun, \\ Jilin Province, China \\ ${ }^{3}$ Department of Ophthalmology, First Hospital of Jilin University, Changchun, \\ Jilin Province, China \\ ${ }^{4}$ Department of Andrology, First Hospital of Jilin University, Changchun, \\ Jilin Province, China \\ Corresponding authors: X.D. Liu / C.W. Lu \\ E-mail: 286539397@qq.com / lucwjlu@126.com \\ Genet. Mol. Res. 15 (1): gmr.15018078 \\ Received November 18, 2015 \\ Accepted January 13, 2016 \\ Published March 24, 2016 \\ DOI http://dx.doi.org/10.4238/gmr.15018078
}

ABSTRACT. Long-term radiation exposure affects human health. lonizing radiation has long been known to raise the risk of cancer. In addition to high doses of radiation, low-dose ionizing radiation might increase the risk of cardiovascular disease, lens opacity, and some other non-cancerous diseases. Low- and high-dose exposures to ionizing radiation elicit different signaling events at the molecular level, and may involve different response mechanisms. The health risks arising from exposure to low doses of ionizing radiation should be re-evaluated. Health workers exposed to ionizing radiation experience low-dose radiation and have an increased risk of hematological malignancies. Reproductive function is sensitive to changes in the physical environment, including ionizing radiation. However, data is scarce regarding the association between occupational 
radiation exposure and risk to human fertility. Sperm DNA integrity is a functional parameter of male fertility evaluation. Hence, we aimed to report sperm quality and DNA damage in men from Jilin Province, China, who were occupationally exposed to ionizing radiation. Sperm motility and normal morphology were significantly lower in the exposed compared with the non-exposed men. There was no statistically significant difference in sperm concentration between exposed and non-exposed men. The sperm DNA fragmentation index was significantly higher in the exposed than the non-exposed men. Chronic long-term exposure to low doses of ionizing radiation could affect sperm motility, normal morphology, and the sperm DNA fragmentation index in the Chinese population. Sperm quality and DNA integrity are functional parameters that could be used to evaluate occupational exposure to ionizing radiation.

Key words: Sperm DNA damage; lonizing radiation; Occupational exposure; Sperm parameter

\section{INTRODUCTION}

Long-term radiation exposure affects the health of the human body. Late-onset effects of exposure to ionizing radiation on health have been identified by long-term, large-scale epidemiological studies (Kamiya et al., 2015). lonizing radiation has long been known to raise the risks of cancer (Abbott, 2015). In addition to high doses of radiation, low-dose ionizing radiation (LDIR) might increase the risk of cardiovascular disease, lens opacity, and some other noncancerous diseases (Hammer et al., 2013; Kamiya et al., 2015; Kreuzer et al., 2015). The authors of previous research have reported that cardiovascular morbidity and mortality may occur decades after ionizing radiation exposure (Yan et al., 2014). The health risks arising from exposure to low doses of ionizing radiation should be re-evaluated (El-Saghire et al., 2013).

Although the response to ionizing radiation-induced DNA damage involves special mechanisms of DNA repair (Yang et al., 2014b), long-term radiation exposure and the late-onset effects of exposure should be taken seriously. Previous studies have shown that health workers occupationally exposed to ionizing radiation experience an increased risk of hematological malignancies (Kumar et al., 2013). lonizing radiation is a classical mutagen and is capable of inducing various kinds of stable and unstable chromosomal aberrations (Vellingiri et al., 2014). Lowand high-dose exposures to ionizing radiation result in different signaling events at the molecular level, and may involve different response mechanisms (Zhang et al., 2014; von Neubeck et al., 2015). However, different LDIR-induced responses may also share the same signal transduction pathways (Tang and Loke, 2015).

Reproductive function is sensitive to changes in the physical environment, including ionizing radiation. However, there is a paucity of data regarding the association between occupational radiation exposure and risk to human fertility (Kumar et al., 2014). Exposure to ionizing radiation leads to a high incidence of de novo mutations in the $Y$ chromosome (Arruda, 2009). There are significant differences in the semen characteristics motility, viability, and morphological abnormality between exposed and non-exposed populations (Kumar et al., 2013).

Sperm DNA integrity is a functional parameter of male fertility evaluation (Tandara et al., 
2014). The sperm DNA fragmentation index (DFI) is a good prognostic marker; a higher sperm DFI may be associated with a poor successful pregnancy rate, even after assisted conception, and may be associated with recurrent loss of the fetus (Venkatesh et al., 2011). Kumar et al. (2013) reported that the level of sperm DNA fragmentation was significantly higher in a group that was occupationally exposed to radiation compared with a non-exposed group. There is a paucity of new data on sperm DNA damage in men from a Chinese population who are occupationally exposed to ionizing radiation. In the present study, we report sperm quality and DNA damage in men from Jilin Province, China, who have been occupationally exposed to ionizing radiation.

\section{MATERIAL AND METHODS}

\section{Patients}

The patients were consecutively recruited among men who sought pre-pregnancy counseling in the andrology outpatient's clinic of the First Hospital of Jilin University. A total of 118 men were recommended for the detection of sperm DNA damage between January 2014 and June 2015. Simultaneously, sperm parameters were detected in all patients.

\section{Questionnaire}

Each patient was provided with a detailed questionnaire on the patients' occupation, working conditions, age, marital history, height, weight, education level, smoking history and frequency, and medical history.

\section{Analysis of sperm parameters}

Sperm concentration and motility were determined by computer-assisted semen analysis. Sperm morphology was evaluated on air-dried smears fixed and stained with Wright-Giemsa, as reported by Liu et al. (2010).

\section{Sperm DNA integrity}

Sperm DNA integrity was investigated by a sperm chromatin dispersion test using a kit for the determination of the DNA fragmentation level in spermatozoa (Boruide Biotechnology Co. Ltd., Shenzhen, China). Sperm possessing nuclei with large or medium halos were considered to have non-fragmented DNA, whereas sperm possessing nuclei with small halos or those degraded and without a halo were considered to have fragmented DNA. The halo size and dispersion patterns were determined by oil immersion bright-field light microscopy at $1000 \mathrm{X}$ magnification, as reported by Fernández et al. (2003) and Qiu et al. (2011). The sperm DFI = number of sperm with fragmented DNA / total number of sperm $\times 100$. A sperm DFI $<25 \%$ is normal.

\section{Statistical analysis}

All data were analyzed using SPSS v.17.0 for Windows (SPSS, Inc., Chicago, IL, USA). Parametric variables were compared by independent sample $t$-tests. All results are reported as means $\pm \mathrm{SD}$ or number (percentage). $\mathrm{P}<0.05$ was considered to be statistically significant. 


\section{RESULTS}

Of the 118 subjects in this study, 46 men were occupationally exposed to ionizing radiation and 72 men were not (the control group). The occupationally exposed men were from various hospitals with diagnostic radiation facilities (mainly computed tomography). All 46 men had operated the equipment for more than two years, and were considered to have been chronically exposed to low-dose radiation, as reported by Kumar et al. (2013).

The characteristics of the men who had been exposed to ionizing radiation and those that had not are shown in Table 1. There were not statistically significant differences in age, height, weight, and smoking habits between the exposed and non-exposed men $(P>0.05)$, and their education level was approximately the same.

Table 1. Characteristics of men who had been occupationally exposed to ionizing radiation and those who had not.

\begin{tabular}{l|c|c|c}
\hline Characteristic & Non-exposed $(\mathrm{N}=72)$ & Exposed $(\mathrm{N}=46)$ & $\mathrm{P}$ value \\
\hline Age $($ years $)$ & $28.86 \pm 3.75$ & $28.26 \pm 3.12$ & 0.377 \\
\hline Height $(\mathrm{cm})$ & $175.25 \pm 3.51$ & $174.78 \pm 4.05$ & 0.508 \\
\hline Weight $(\mathrm{kg})$ & $77.79 \pm 3.67$ & $78.13 \pm 3.96$ & 0.636 \\
\hline Smoking & $3.78 \pm 2.54$ & $3.70 \pm 3.04$ & 0.879 \\
\hline Cigarettes/day & $4.06 \pm 2.25$ & $3.50 \pm 2.79$ & 0.259 \\
\hline Years & $27(37.5 \%)$ & $20(43.5 \%)$ & \\
\hline Education level & $39(54.2 \%)$ & $26(56.5 \%)$ & \\
\hline Graduate & $6(8.3 \%)$ & 0 & \\
\hline University & Try &
\end{tabular}

${ }^{*} \mathrm{P}<0.05$ compared with non-exposed group.

The sperm parameters of the exposed and non-exposed men are shown in Table 2. Sperm motility and normal morphology were significantly lower in the exposed compared with the non-exposed men $(P<0.001)$. There were not statistically significant differences in sperm concentration between the exposed and non-exposed men $(P>0.05)$.

\section{Table 2. Sperm parameters of men exposed to ionizing radiation.}

\begin{tabular}{l|c|c|c}
\hline Sperm parameters & Non-exposed $(\mathrm{N}=72)$ & Exposed $(\mathrm{N}=46)$ & $\mathrm{P}$ value \\
\hline Concentration $\left(\times 10^{6} / \mathrm{mL}\right)$ & $74.50 \pm 13.67$ & $73.84 \pm 14.80$ & 0.434 \\
\hline Motility $(\%)$ & $25.19 \pm 3.60$ & $20.85 \pm 3.41$ & $<0.001^{*}$ \\
\hline Normal morphology $(\%)$ & $16.72 \pm 5.67$ & $10.04 \pm 3.63$ & $<0.001^{*}$ \\
\hline
\end{tabular}

${ }^{*} \mathrm{P}<0.001$ compared with non-exposed group.

Sperm DFI was significantly higher in the exposed compared with the non-exposed men $(P<0.001$; Table 3).

Table 3. Sperm DNA fragmentation index of men exposed to ionizing radiation.

\begin{tabular}{l|c|c|c}
\hline Sperm parameters & Non-exposed $(\mathrm{N}=72)$ & Exposed $(\mathrm{N}=46)$ & $\mathrm{P}$ value \\
\hline Sperm DFI $(\%)$ & $14.68 \pm 6.32$ & $29.43 \pm 4.57$ & $<0.001^{*}$
\end{tabular}

$\mathrm{DFI}=\mathrm{DNA}$ fragmentation index; ${ }^{*} \mathrm{P}<0.001$ compared with non-exposed group.

\section{DISCUSSION}

Chronic long-term exposure to low doses of ionizing radiation could increase chromosomal aberrations and sister chromatid exchange frequencies (Cardoso et al., 2001; Santovito et al., 2014). 
Ionizing radiation exposure induces highly lethal DNA double-strand breaks in all phases of the cell cycle (Hunt et al., 2013). The occupationally exposed individuals showed higher frequencies of dicentric and acentric chromosomes compared with the normal controls (Jha and Sharma, 1991). DNA strand breaks accumulate for quite a long time after ionizing radiation exposure, indicating the development of genetic instability and an increase in carcinogenic risk for organisms exposed to a combination of harmful environmental factors (Mikhailenko and Muzalov, 2013). Sperm function is sensitive to ionizing radiation or certain environmental factors.

Sperm concentration, motility, and morphology are all useful in diagnosing male infertility (Guzick et al., 2001). Hence, we studied sperm quality and DNA damage in men from a Chinese population who were occupationally exposed to ionizing radiation. The characteristics of age, height, weight, and smoking habits did not differ significantly between those who were exposed to ionizing radiation and those who were not. Sperm motility and normal morphology were significantly lower in the exposed than in the non-exposed men. However, there was no statistically significant difference in sperm concentration. These results were consistent with the literature (Kumar et al., 2013).

Sperm DNA integrity is a functional parameter of male fertility evaluation (Tandara et al., 2014). A molecular epidemiology approach and/or the use of integrated biomarkers of sperm quality and sperm DNA damage might be useful for future research focused on the low-to-moderate dose range for diagnostic and professional exposures (Latini et al., 2012). Chater et al. (2007) reported that ionizing radiation triggers apoptosis in testicular germ cells. Kumar et al. (2013) reported that the level of sperm DNA fragmentation was significantly higher in those that were occupationally exposed to ionizing radiation. Binsaleh et al. (2015) reported that Saudi male partners had increasing levels of sperm DFI (25.4), and there was a high percentage of sperm DNA damage in the male partner in infertile Saudi couples. In our study, the sperm DNA fragmentation index was significantly higher in the exposed compared with the non-exposed men. This result was consistent with the literature.

Low-dose ionizing radiation induces many late post-radiation effects by several pathways. Chronic oxidative stress is the main cause of the late post-radiation effects, including cancer, and this makes it an important adverse effect of exposure to ionizing radiation (Szumiel, 2015). Delayed mitochondrial reactive oxygen species production may cause some cell death after irradiation (Kobashigawa et al., 2015). LDIR could provide a potential mechanism, stimulate natural killer cells, and induce direct expansion and activation (Yang et al., 2014a). Borghini et al. (2015) reported evidence for a possible role of circulating cell-free DNA as a relevant biomarker of cellular damage induced by exposure to chronic low-dose radiation.

Computed tomography is a frequently used imaging modality that contributes to a tenfold increase in radiation exposure to the public when compared with other medical imaging modalities (Kanagaraj et al., 2015). The average level of radiation experienced by a citizen of the USA in a year has doubled, mostly because of medical procedures. Computed-tomography scans are to blame for most of the rise (Abbott, 2015). Some studies reinforce the relevance of the biomonitoring of hospital workers who are chronically exposed to ionizing radiation (Santovito et al., 2014). Chromosomal damage leading to the formation of micronucleated lymphocytes is more frequent in hospital workers who are exposed to ionizing radiation (Bouraoui et al., 2013). The genotoxic effects of ionizing radiation remain for decades after exposure in subjects exposed to low-dose radiation (Sakly et al., 2013; Han et al., 2014).

\section{CONCLUSIONS}

In summary, chronic long-term exposure to low doses of ionizing radiation could affect 
sperm motility and normal morphology in the Chinese population. The sperm DFI was significantly higher in the men who had been occupationally exposed to ionizing radiation. Occupational exposure to ionizing radiation should be taken seriously. Sperm DNA integrity could be a functional parameter for the evaluation of occupational exposure.

\section{Conflicts of interest}

The authors declare no conflict of interest.

\section{ACKNOWLEDGMENTS}

We would like to express our sincere gratitude to all the staff of the andrology laboratory at the First Hospital of Jilin University for their excellent work.

\section{REFERENCES}

Abbott A (2015). Researchers pin down risks of low-dose radiation. Nature 523: 17-18. http://dx.doi.org/10.1038/523017a

Arruda JT (2009). Occurrence of mutations in loci linked to $Y$ chromosome in the offspring born to individuals exposed to ionizing radiation. Genet. Mol. Res. 8: 938. http://dx.doi.org/10.4238/vol8-3ta021

Binsaleh S, Al-Qahtani R, Madbouly K, Isa AM, et al. (2015). Evaluation of sperm DNA damage in men from infertile Saudi couples. J. Reprod. Med. 60: 135-140.

Borghini A, Mercuri A, Turchi S, Chiesa MR, et al. (2015). Increased circulating cell-free DNA levels and mtDNA fragments in interventional cardiologists occupationally exposed to low levels of ionizing radiation. Environ. Mol. Mutagen. 56: 293300. http://dx.doi.org/10.1002/em.21917

Bouraoui S, Mougou S, Drira A, Tabka F, et al. (2013). A cytogenetic approach to the effects of low levels of ionizing radiation (IR) on the exposed Tunisian hospital workers. Int. J. Occup. Med. Environ. Health 26: 144-154. http://dx.doi.org/10.2478/ s13382-013-0084-4

Cardoso RS, Takahashi-Hyodo S, Peitl P, Jr., Ghilardi-Neto T, et al. (2001). Evaluation of chromosomal aberrations, micronuclei, and sister chromatid exchanges in hospital workers chronically exposed to ionizing radiation. Teratog. Carcinog. Mutagen. 21: 431-439. http://dx.doi.org/10.1002/tcm.1030

Chater S, Amara S, Moussata D, Bozec A, et al. (2007). Differential effects of ionizing radiation and platinum-derivative chemotherapy on apoptotic pathways in testicular germ cells. Int. J. Radiat. Biol. 83: 269-278. http://dx.doi. org/10.1080/09553000701227573

El-Saghire H, Michaux A, Thierens H and Baatout S (2013). Low doses of ionizing radiation induce immune-stimulatory responses in isolated human primary monocytes. Int. J. Mol. Med. 32: 1407-1414.

Fernández JL, Muriel L, Rivero MT, Goyanes V, et al. (2003). The sperm chromatin dispersion test: a simple method for the determination of sperm DNA fragmentation. J. Androl. 24: 59-66.

Guzick DS, Overstreet JW, Factor-Litvak P, Brazil CK, et al.; National Cooperative Reproductive Medicine Network (2001). Sperm morphology, motility, and concentration in fertile and infertile men. N. Engl. J. Med. 345: 1388-1393. http://dx.doi. org/10.1056/NEJMoa003005

Hammer GP, Scheidemann-Wesp U, Samkange-Zeeb F, Wicke H, et al. (2013). Occupational exposure to low doses of ionizing radiation and cataract development: a systematic literature review and perspectives on future studies. Radiat. Environ. Biophys. 52: 303-319. http://dx.doi.org/10.1007/s00411-013-0477-6

Han L, Zhao FL, Sun QF, Wang P, et al. (2014). Cytogenetic analysis of peripheral blood lymphocytes, many years after exposure of workers to low-dose ionizing radiation. Mutat. Res. Genet. Toxicol. Environ. Mutagen. 771: 1-5. http://dx.doi. org/10.1016/j.mrgentox.2014.06.003

Hunt CR, Ramnarain D, Horikoshi N, lyengar P, et al. (2013). Histone modifications and DNA double-strand break repair after exposure to ionizing radiations. Radiat. Res. 179: 383-392. http://dx.doi.org/10.1667/RR3308.2

Jha AN and Sharma T (1991). Enhanced frequency of chromosome aberrations in workers occupationally exposed to diagnostic X-rays. Mutat. Res. 260: 343-348. http://dx.doi.org/10.1016/0165-1218(91)90020-M

Kamiya K, Ozasa K, Akiba S, Niwa O, et al. (2015). Long-term effects of radiation exposure on health. Lancet 386: 469-478. http://dx.doi.org/10.1016/S0140-6736(15)61167-9 
Kanagaraj K, Abdul Syed Basheerudeen S, Tamizh Selvan G, Jose MT, et al. (2015). Assessment of dose and DNA damages in individuals exposed to low dose and low dose rate ionizing radiations during computed tomography imaging. Mutat. Res. Genet. Toxicol. Environ. Mutagen. 789-790: 1-6. http://dx.doi.org/10.1016/j.mrgentox.2015.05.008

Kobashigawa S, Kashino G, Suzuki K, Yamashita S, et al. (2015). Ionizing radiation-induced cell death is partly caused by increase of mitochondrial reactive oxygen species in normal human fibroblast cells. Radiat. Res. 183: 455-464. http:// dx.doi.org/10.1667/RR13772.1

Kreuzer M, Auvinen A, Cardis E, Hall J, et al. (2015). Low-dose ionising radiation and cardiovascular diseases--Strategies for molecular epidemiological studies in Europe. Mutat. Res. Rev. Mutat. Res. 764: 90-100. http://dx.doi.org/10.1016/j. mrrev.2015.03.002

Kumar D, Salian SR, Kalthur G, Uppangala S, et al. (2013). Semen abnormalities, sperm DNA damage and global hypermethylation in health workers occupationally exposed to ionizing radiation. PLoS One 8: e69927. http://dx.doi. org/10.1371/journal.pone.0069927

Kumar D, Salian SR, Kalthur G, Uppangala S, et al. (2014). Association between sperm DNA integrity and seminal plasma antioxidant levels in health workers occupationally exposed to ionizing radiation. Environ. Res. 132: 297-304. http:// dx.doi.org/10.1016/j.envres.2014.04.023

Latini G, Dipaola L, Mantovani A and Picano E (2012). Reproductive effects of low-to-moderate medical radiation exposure. Curr. Med. Chem. 19: 6171-6177. http://dx.doi.org/10.2174/0929867311209066171

Liu RZ, Gao JC, Zhang HG, Wang RX, et al. (2010). Seminal plasma zinc level may be associated with the effect of cigarette smoking on sperm parameters. J. Int. Med. Res. 38: 923-928. http://dx.doi.org/10.1177/147323001003800318

Mikhailenko VM and Muzalov II (2013). Exogenous nitric oxide potentiate DNA damage and alter DNA repair in cells exposed to ionising radiation. Exp. Oncol. 35: 318-324.

Qiu Y, Wang LG, Jia YF, Yang DT, et al. (2011). Effects of the crude extract of Polygala tenuifolia Willd on human sperm in vitro. J. Zhejiang Univ. Sci. B 12: 448-454. http://dx.doi.org/10.1631/jzus.B1000347

Sakly A, Ayed Y, Chaari N, Akrout M, et al. (2013). Assessment of chromosomal aberrations and micronuclei in peripheral lymphocytes from tunisian hospital workers exposed to ionizing radiation. Genet. Test. Mol. Biomarkers 17: $650-655$. http://dx.doi.org/10.1089/gtmb.2012.0111

Santovito A, Cervella P and Delpero M (2014). Increased frequency of chromosomal aberrations and sister chromatid exchanges in peripheral lymphocytes of radiology technicians chronically exposed to low levels of ionizing radiations. Environ. Toxicol. Pharmacol. 37: 396-403. http://dx.doi.org/10.1016/j.etap.2013.12.009

Szumiel I (2015). lonizing radiation-induced oxidative stress, epigenetic changes and genomic instability: the pivotal role of mitochondria. Int. J. Radiat. Biol. 91: 1-12. http://dx.doi.org/10.3109/09553002.2014.934929

Tandara M, Bajić A, Tandara L, Bilić-Zulle L, et al. (2014). Sperm DNA integrity testing: big halo is a good predictor of embryo quality and pregnancy after conventional IVF. Andrology 2: 678-686. http://dx.doi.org/10.1111/j.2047-2927.2014.00234.x

Tang FR and Loke WK (2015). Molecular mechanisms of low dose ionizing radiation-induced hormesis, adaptive responses, radioresistance, bystander effects, and genomic instability. Int. J. Radiat. Biol. 91: 13-27. http://dx.doi.org/10.3109/0955 $\underline{3002.2014 .937510}$

Vellingiri B, Shanmugam S, Subramaniam MD, Balasubramanian B, et al. (2014). Cytogenetic endpoints and Xenobiotic gene polymorphism in lymphocytes of hospital workers chronically exposed to ionizing radiation in Cardiology, Radiology and Orthopedic Laboratories. Ecotoxicol. Environ. Saf. 100: 266-274. http://dx.doi.org/10.1016/j.ecoenv.2013.09.036

Venkatesh S, Singh A, Shamsi MB, Thilagavathi J, et al. (2011). Clinical significance of sperm DNA damage threshold value in the assessment of male infertility. Reprod. Sci. 18: 1005-1013. http://dx.doi.org/10.1177/1933719111401662

von Neubeck C, Geniza MJ, Kauer PM, Robinson RJ, et al. (2015). The effect of low dose ionizing radiation on homeostasis and functional integrity in an organotypic human skin model. Mutat. Res. 775: 10-18. http://dx.doi.org/10.1016/j. mrfmmm.2015.03.003

Yan X, Sasi SP, Gee H, Lee J, et al. (2014). Cardiovascular risks associated with low dose ionizing particle radiation. PLoS One 9: e110269. http://dx.doi.org/10.1371/journal.pone.0110269

Yang G, Kong Q, Wang G, Jin H, et al. (2014a). Low-dose ionizing radiation induces direct activation of natural killer cells and provides a novel approach for adoptive cellular immunotherapy. Cancer Biother. Radiopharm. 29: 428-434. http://dx.doi. org/10.1089/cbr.2014.1702

Yang QY, Li JH, Wang QY, Wu Y, et al. (2014b). MTA1 promotes cell proliferation via DNA damage repair in epithelial ovarian cancer. Genet. Mol. Res. 13: 10269-10278. http://dx.doi.org/10.4238/2014.December.4.21

Zhang Q, Matzke M, Schepmoes AA, Moore RJ, et al. (2014). High and low doses of ionizing radiation induce different secretome profiles in a human skin model. PLoS One 9: e92332. http://dx.doi.org/10.1371/journal.pone.0092332 